\title{
Ship waste management along the Danube: the way towards an International Danube Ship Waste Convention
}

\author{
H. Berger ${ }^{1}$, I. Horvat ${ }^{2} \&$ G. Simongáti ${ }^{3}$ \\ ${ }^{1}$ Via donau - Österreichische Wasserstraßen-Gesellschaft mbH, Austria \\ ${ }^{2}$ PAV, Public Institution Port Authority Vukovar, Croatia \\ ${ }^{3}$ KTI Institute for Transport Sciences Non Profit Ltd., Budapest
}

\begin{abstract}
As the second longest river in Europe, the Danube connects 10 countries on its way to the Black Sea, being an international waterway used by vessels of different provenience. Thus, there are in fact 10 different social, economic and political systems at work when dealing with the waste generated by the vessels. This uncoordinated approach has affected the manner in which ship borne waste are dealt with. Policies and strategies on international and national level call for state of the art, economic and environmental viable solutions for managing waste. Taking into account this context, much effort has been made at EU level in order to find suitable solutions for the South-Eastern part of Europe. The studies and projects initiated in this respect have led to the conclusion that an International Danube Ship Waste Convention needs to be developed. Such a convention - which basis is elaborated in the frame of the EU funded project CO-WANDA - assumes the implementation of a uniform system for the collection and treatment of oily and greasy ship wastes along the River Danube. The establishment and maintenance of the necessary network of reception facilities (mobile bilge water collection vessels, shore-based reception stations and treatment facilities) is certainly cost-intensive. Therefore, a financing model is necessary, which should incorporate the polluter pays principle, encouraging waste prevention, as well as the principle of indirect payment, thus discouraging an evasion of the deposit of waste. To give an insight into the work, that has been done in CO-WANDA, this paper will address advantages and disadvantages of two different approaches to ship waste management, describe
\end{abstract}


legal and administrative framework conditions, show data gathered from vessels along the whole waterway and outline the technical background and important steps for the implementation of the international convention.

Keywords: Danube, waste management system, ship borne wastes, convention, harmonisation, Electronic Vignette System.

\section{Introduction}

The paper at hand deals with the topic of ship waste management along the Danube in the frame of the project "Convention for Waste management for Inland Navigation on the Danube - (CO-WANDA) which is being implemented from October 2012 till September 2014 with fundamental support of the European Union's South East Europe Transnational Cooperation Programme. Although the project has not been finished yet, substantial findings have been made and key aspects for future development can be outlined.

\section{Legal background and the need for an international convention}

The superior goal of the CO-WANDA project is to provide basic arguments and documents for policymakers in order to regulate ship waste disposal on the Danube in a transnational and harmonized manner. That goal is planned to be reached by preparing an International Danube Ship Waste Convention (IDSWC) - a unified document for transnational ship waste management along the Danube. This document is going to provide a basis for stakeholders and policymakers on how to regulate ship waste disposal along the River Danube for the different types of wastes generated on-board the vessels, such as oily and greasy wastes, cargo wastes or waste waters. Emphasis has to be put on the definition of a financing system including a system for international financial clearance.

An international coordinated waste management system for inland navigation on the Danube is in discussion for almost thirty years. At the same time different international legal systems are in force overlapping territorially in their implementation. Adding to it the effect of every country's national legal framework and bodies it is obvious why one of the main problems in Danube riparian countries is absence of the unified regulations which could be implemented in a harmonized way.

During WANDA project [1] it was discovered that without appropriate transnational agreed legal instrument between Danube riparian countries ship waste management will be still uncoordinated with fundamental risks for entire ecosystem. In all Danube riparian countries there is a lack of legal binding requirements, consequent controlling and monitoring mechanism of waste collection, disposal and treatment, user-friendly and efficient infrastructure, transnationally coordinated re-financing schemes for costs incurred by ship 
waste handling and appropriate awareness about environmental protection. Hazardous and non-hazardous ship wastes like oil, grease, batteries, plastic, paints, solvents are disposed more or less uncontrolled in large sections of the Danube by the vessels crew.

In some of Danube riparian countries it is not allowed to dispose waste from foreign vessels because of non-harmonized interpretation of Basel Convention on the Control of Transboundary Movements of Hazardous Wastes and Their Disposal and the EC 1013/2006 Regulation on Shipments of Waste. This could be solved only by an international convention, which shall fill the gap of the international and national framework, thereby developing provisions which can be practically applied.

For all afore mentioned reasons evaluation of national and international legal-administrative aspects has to be considered for the development of IDSWC. After clarification of the framework the basic structure for the treaty was agreed, on the basis of which the contents of the IDSWC was drafted. The contents itself will include rules for ship wastes handling, financing of services and definition of international balances as well as basic administrative procedures.

For the IDSWC preparation information exchange with international organizations as Danube Commission, International Sava River Basin Commission, Central Commission on Navigation on the Rhine, European Commission is necessary. The IDSWC will demand also a harmonization with EU Strategy for Danube River, which is part of the administrative framework of the Region. In order to ensure implementation of results on national level, involvement of national and international experts is foreseen in an already established "International Implementation Board". Once the technical preparation of the IDSWC is finished, strategies for implementation shall be prepared in every participating country as well as a Joint Action Plan where goals and measures for IDSWC will be described on transnational level.

Without doubt, a role model for the development and implementation in the Danube Region is a similar convention, which is in force since the end of 2009 in the Rhine Region. Danube and Rhine River systems are connected but provisions of the Rhine Region cannot be implemented without adaptation on the Danube due to significant socio-economic differences. Vessels navigating both rivers shall have harmonized user-friendly and well-coordinated ship waste management system. Lessons learned in the Rhine Region are the subject of investigation within the CO-WANDA project.

\section{Ship waste management models in Europe}

\subsection{CDNI for the Rhine region}

On November 1st, 2009 the "convention on the collection, deposit and reception of waste produced during navigation on the Rhine and inland waterways" $(\mathrm{CDNI})$ has come into force after the ratification procedures had been finalised after 13 years. 
The CDNI [2], which has been signed in 1996 by six Western European countries, contains harmonised rules for the management of ship waste generated on board of inland waterway vessels. The geographical scope covers all inland waterways in Germany, Belgium and the Netherlands, the Mosel in Luxembourg, parts of the Rhine in Switzerland and parts of French waterways. The goals were to support environmental protection, contribute to the safety and health of the crew and users of inland waterway transport. Harmonisation of rules on international level was recognized to be of high importance in order to avoid distortion of competition. Besides the core text, which contains general rules, implementation regulations are detailed in technical annexes, which have been grouped according to waste type, each of which entails varying handling practices, responsibilities and financial consequences. The first group includes oily and greasy ship waste, including bilge water (oil-water mixture, containing usually between 10 and $20 \%$ of waste oil, used oils and solid oily and greasy ship waste). The second group are cargo related waste, third all other types of ship waste, such as household refuse, domestic waste water or batteries. As a general principle, the polluters shall pay the costs for the disposal of the waste, hence, vessel owners have to pay the fees for disposal of oily and greasy ship waste. For cargo related waste, the charterer or consignee has to pay the cost and for other ship waste it depends of type of the waste, however, in most cases a regulation on national level is foreseen, e.g. for domestic refuse from passenger vessels.

Besides the handling practices and financing principles, the CDNI also contains the obligation for member states to develop and provide a sufficient dense, internationally harmonised network of reception facilities, the costs of which shall be reimbursed by the fees collected from the sector. Indeed, the financing model for oily and greasy ship waste is one of the main pillars of the CDNI. Basically, it should fulfil the principles of indirect payment, in order to avoid evasive reactions, include the polluter-pays principle and encourage waste prevention, which are partly contradictory. The approach, which has been chosen, is a levy on gas oil, which has the height of 7.5 Euro/1000 litres of bunkered gas oil. The fee is charged with an ECO-Card during bunkering, however, since the cards are not checked, free riders can use this system as well, which could be a problem on the system borders, such as German Danube. The corresponding amount of the charged fee is debited from a special bank account of the vessel operators by a "National Institution", which organizes waste collection services in the country. Since disposed waste amounts, costs for waste disposal and amounts of collected disposal fee vary between the countries, equalization payments are carried out. In the WANDA project, detailed analysis on application of this model on the Danube River has been made, however, the following serious disadvantages have been identified: The decentralized debiting of the disposal fee causes high administrative efforts. Moreover, the system does not solve the problem of free riders, actually, as long as the collected fees cover the disposal costs, they are accepted in the system. Another aspect, which still leads to discussions of the model, is, that there is no proofed correlation between gasoil use and bilge water generation. Although it can be assumed, that an engine 
utilized to a higher degree generates more waste, this effect can be buffered to a great extent by shaft sealings kept in good condition by proper maintenance of the vessel. Moreover, tankers also use gas oil for their heating system, modern passenger vessels usually are equipped with separate tanks for waste oil, which can have an economic value, and low amounts of bilge water, the collection and treatment of which is costly. Since the height of the total disposal fee is not limited, vessel with high gas oil consumption might pay a disproportional portion. To sum up, application of the gas oil system seems questionable, also taking into consideration the fact that a black market for gas oil along the Danube might exist. As such, a Vignette system for charging the fees was recommended to be further developed along the Danube [3].

\subsection{The danubian approach in CO-WANDA}

\subsubsection{Development of a financing model for the Danube}

The financing of waste collection services represents a crucial factor in developing and providing user friendly, state-of the art waste reception facilities. Thus, developing an approach which can be applied along the River Danube, which crosses ten countries with a great variation with regards to the socio-economic background, environmental awareness, handling practices of waste and technical standards and equipment indeed is a big challenge. As a first step, the basic requirements for a financing model (FM) have been identified. In fact, a FM should cover the costs for operation of waste reception facilities, should be applicable on international level and should be compatible to the system used in the Rhine Region. It's operation should be cheap and fail proof. At the same time, the principles of polluter-pays, indirect payment and waste prevention should be incorporated. Several alternatives were pre-investigated, such as development of a comprehensive port fee system, a distance based fee and others [3]. Investigations showed that a Vignette System fulfilled the implementation criteria best. One main advantage of the system is, that the concept is flexible; charging can be separated from determination of the fee. Vignettes can be checked directly at the waste reception facilities (WRFs) when delivering the waste which discourages free-riding. If a legal obligation for vessels to carry a vignette is developed, as it is foreseen, the incentive for evasive reactions might decrease. Another advantage is that the height of the fee can be determined for different vessel categories, in principal also waste prevention measures could be encouraged by offering reduced vignettes to environmentally friendly vessels.

However, it has to be stated, that a lack of data not only with regards to waste management issues but also with regards to vessel numbers and fleet structure along the Danube exist. As a consequence, the FM has to be developed stepwise, including skippers, fleet operators and authorities.

Thus, pilot tests were developed and implemented in Austria, Slovakia, Hungary, Croatia, Romania and Bulgaria in 2013 with the aim to raise awareness, gather data and test implementation of such a vignette system. Vessels, which participated in the tests, got a vignette free of charge, which 
entitled them to dispose their waste at selected WRFs without further payment. All in all, more than 150 vessels registered in 8 weeks disposing more than $400 \mathrm{~m}^{3}$ of bilge water, $23 \mathrm{~m}^{3}$ waste oil and 2 tons of other oily and greasy ship waste.

\subsubsection{Technical solutions}

3.2.2.1. Electronic Vignette System (EVS) The proposed Vignette System mentioned in the previous chapter can be established in different ways. In the beginning of the CO-WANDA project several alternatives for the vignette (be made of paper, be a stamp in the oil control log or be electronic readable plastic cards, etc.) were analyzed against various criteria and finally the electronic system with a web interface was selected. Based on the available knowledge and information at the beginning of the project, a system specification was elaborated, a prototype was developed and was extensively tested in pilot tests mentioned before. After registration, the skippers - giving useful information to project partners about wastes generated onboard - were entitled to download a virtual vignette by which they were allowed free of charge to dispose their oily and greasy ship wastes at dedicated WRFs during the test timeframe.

The structural organization of the EVS is in full accordance with the Financial Model (Figure 1). The three interest groups (vessel/fleet operators, waste collectors, Coordinator) have access to their own part at the web interface trough which they either can send registration and data, download the vignette, send reports about waste collection or supervise the whole system, according to their specific role. (During the test, project partners played the role of the Coordinator)

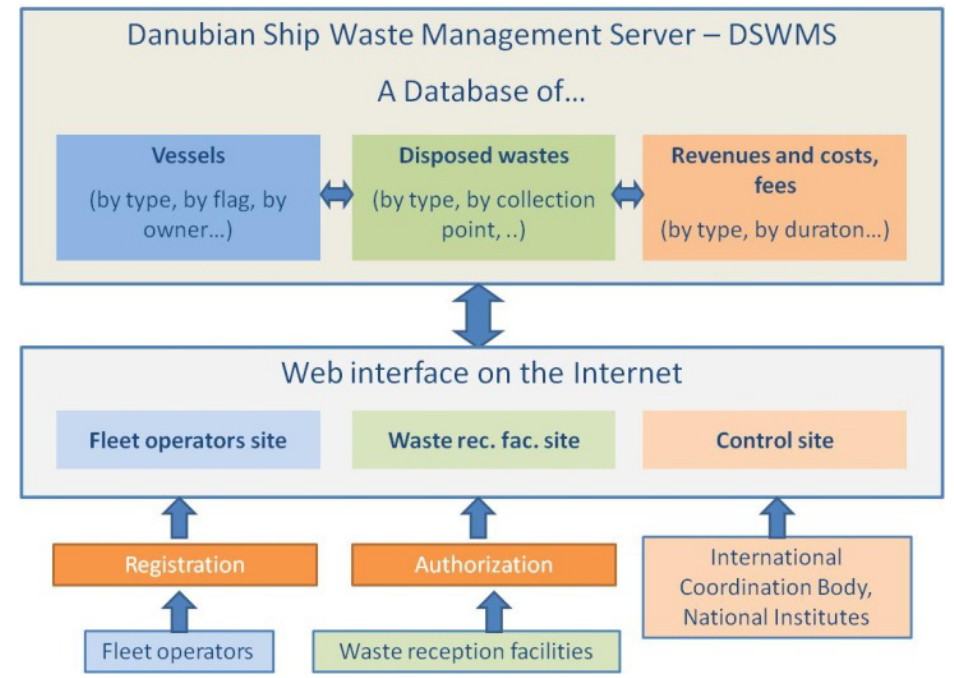

Figure 1: Structure of the EVS. 
The test justified the selection of the EVS, and showed that it is an excellent solution for such a purpose and is widely appreciated among the skippers. The test did not only prove the advantages of the system (fully electronic data processing, harmonized and transparent system, low overall cost, etc.), but marked the direction of improvements as well. In the future version of the EVS modules like electronic payment for the vignettes, connection to the European Hull Database for vessel data inquiry, integration and harmonization of national waste reporting, network optimization, balancing system are planned to be implemented. (Some of these were unnecessary or impossible to incorporate for the test version). Only such a modern, but sufficiently complex system can ensure the appropriate administration of the internationally harmonized ship waste collection system.

3.2.2.2. Optimization of WRFs' network It is obvious that the international harmonization is necessary not only on the legal field of ship waste collection but with regards to the network of the collection facilities, too. So far, the Danube-riparian countries established and developed the reception of wastes only on national level. As a result, an international development concept does not exist and hence the already existing reception facilities are harmonized neither in technology applied nor in capacity available. All this means that the available services offered for the skippers are not synchronized and the technically and nautically sufficient and economically viable operation of an international system is not ensured. In order to provide the skippers with a more user-friendly network while keeping the basic requirements of the environmental protection, the optimization of network elements on international level is inevitable. Hence optimization here means the definition of a sufficient dense network which ensures an acceptable service level for the skippers with a total cost that can be reimbursed by the revenues of selling vignettes and facilitates the highest willingness of legal disposal.

The input parameters for the optimization are as follows: annual and/or average waste amounts per waste and vessel type, geographical distribution of waste disposal, location, applied technology and capacity of existing and potential collection points, definition of vessel categories and number of vessels buying vignettes, cost structure (fix and variable costs) of service types offered by existing and potential collection points with best available technology. With regards to ship waste's collection, three main technologies (collection vessels, stationary facilities and suction trucks) are now used, however further differentiation of service types can be given by taking opening hours and other offered services into consideration.

As a function for determination of the optimal network does not exist, the optimization has to be made by trial and error. With the input parameters listed above, the annual total cost of a network variation (alternative) can be calculated. The cover of the costs can be examined either by the comparison with the revenues given by pre-defined vignette prices or on the basis of economical vignette price calculations. Beside by the costs, it is also important to evaluate the alternatives by some various criteria expressing the effectiveness/goodness of 
the whole network. Such criteria are the coverage, availability, capacity utilization, service level, etc. The alternatives are easily assessed by one of the multi-criteria decision aiding methods.

For performing the numerous calculations to be able to find the optimum, a simulation software was developed in the frame of the CO-WANDA project. In the software, the assessment by the costs and effectiveness - with pre-defined thresholds for accepted levels - are shown simultaneously as it can be seen on Figure 2. Beside the selection of acceptable network variations (like A1), with this form the relations of the alternatives to each other can be visualized easily. (Of course, the software can provide all other quantifiable results, as well.)

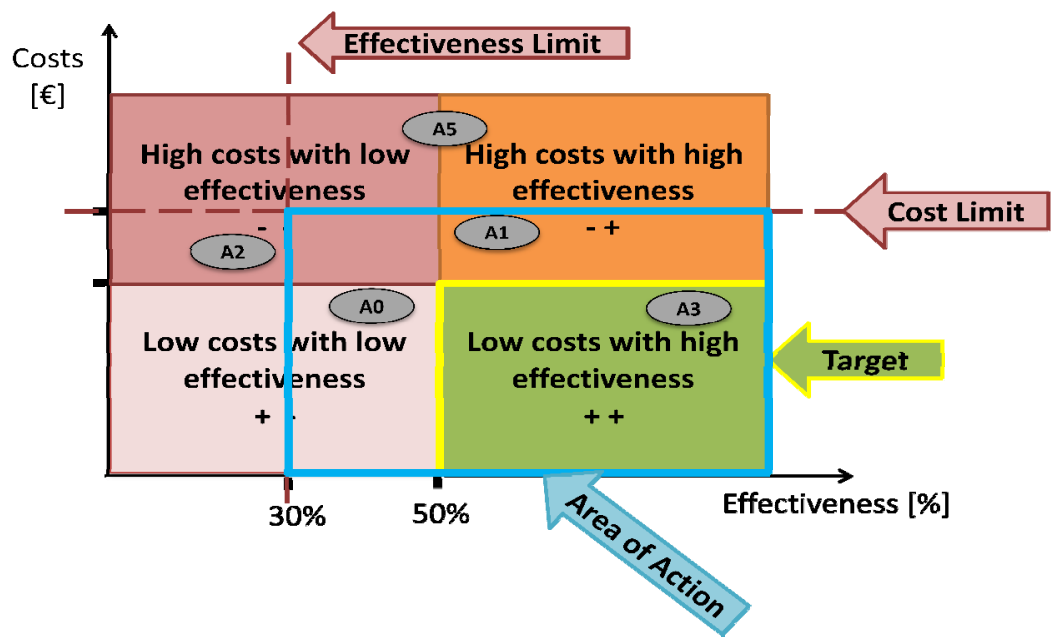

Figure 2: Cost-effectiveness analysis in the simulation software.

During the project work it was realized that some of the input parameters are not available at the moment. Therefore, in the proposal of the convention only the methodology can be incorporated, the result of the optimization based on numerous and rather rough estimation done in the project frame is just an example for the application.

\subsubsection{Handling practices onboard}

Important part of preparing the technical background for the IDSWC is investigation and the analysis of waste management and pre-treatment practices on-board cargo and passenger vessels. The term "pre-treatment" means handling practices carried out on-board vessels that support the collection following or disposal procedures. It is a subsequent step after "waste prevention" but is prior to the steps of preparing for re-use and recycling.

Investigation of handling practices was done in Austria, Slovakia, Hungary, Croatia, Romania and Bulgaria. The main goal was to exchange the necessary information about the waste management activities on-board with national fleet operators and skippers in order to be able to integrate the users' needs into the national concepts elaborated and into the IDSWC. 
The methodology of investigation was interview by unified questionnaires translated into all participating countries languages. The questionnaires were filled personally by skippers or fleet operators or the interviews were made by telephone or by visits onboard and also questionnaires were distributed on Austrian locks. The research is finalized, although analysis in Romania and Bulgaria is still in progress and in Austria, Slovakia, Croatia and Hungary is prepared, so in this paper only the analyzed results from afore mentioned countries shall be presented.

Combining the data from National Reports [4-7] it can be said that in afore mentioned four countries we have information about handling practices from around 176 cargo and 18 passenger vessels. It is important to say that the amount of bilge water generated on inland vessels is influenced by the age, construction, equipment and maintenance of the vessels as well as the demanded engine activity, which itself depends on several other factors (upstream or downstream way, cargo load, etc.). Also, in the case of the passenger vessels it could be useful to separate cabin vessels and smaller passenger liners/cruising boats because first group of vessels is rather new and in the second group they are older, some more then 30 years.

From the information gained by the Questionnaire we can state the following, although quite general information:

- on most of the cargo and passenger vessels there is no appointed person for waste management on-board,

- majority of the crew on-board is instructed how to deal with waste,

- almost all (above 90\%) of vessels collect oily and greasy water (bilge water) in the bilge room,

- half of the ships collect waste oils in the bilge room,

- third of vessels have oil-water separators to pre-treat bilge water before they discharge it directly into the waterway; this solution can be seen not to be state of the art, since water protection legislation foresees stronger limit values than can be reached,

- the amount of vessels with separate bins for collection of waste oil and oily rags is between $66-90 \%$,

- more than half of vessels have separate bins for residual waste and recyclables, in Hungary $80 \%$ of them, although not all types of waste are collected separately,

- waste water could be treated by usage of on-board storage tanks, on-board purification plants or by discharging the waste water into the waterway; most of the cargo vessels discharge into waterway, wash the vessels outside ports; due to rather old fleet, most of the vessels do not have storage tanks on-board,

- cargo residues are mainly washed after the type of cargo is changed outside ports,

- regarding the locations of disposal there is lack of oily and greasy disposal points, (in some countries, former, state-owned companies operate their own facilities, other operators still have to organize the disposal by themselves, which can also be done in other countries), 
- overall opinion is that it is easy to dispose waste,

- $\quad$ oily and greasy waste is disposed mostly every six months (more than $50 \%$ of vessels) or every three months $(40 \%)$; domestic waste is disposed most frequently, weekly.

\section{The proposed convention and its implementation}

\subsection{Structure of the convention}

The goal of the proposed International Danube Ship Waste Convention (IDSWC) is to provide a harmonized, legally binding framework for the management of the different types of ship waste. The structure itself is in line with the CDNI to a great extent, which shall help to reach a harmonized system wherever feasible, such as for cargo related waste.

The draft agreement consists of the core text, two appendices and several schedules. Whereas the core text defines the principles, technical provisions are detailed in the Appendices. The core text itself is split into general provisions, particular provisions and final clauses, which, all in all consist of 22 articles. The general provisions include definitions used later on in the text and the geographical scope, whereas the particular provisions focus on obligations incumbent on the contracting parties - which means the states accessing the IDSWC - obligations and rights of the parties concerned, such as skippers. Moreover, procedural aspects, sanctions and provisions covering aspects of public international law are put into the main text. From a contents point of view, the structure deals with three different groups of ship waste, namely oily and greasy waste generated from the operation of the vessel, cargo related waste and other waste generated from the operation of the vessel, such as domestic waste water and sludge, special waste occurring from maintenance operation, e.g. paints, batteries, solvents and the like.

One of the most important rules is, that a discharge of waste generated on board or parts of cargo into the waterway is prohibited, exemptions can only be made in line with the rules set out in the appendices.

In order to ensure compliance with this prohibition, the states commit themselves to install a sufficiently dense network of waste reception facilities, which shall be coordinated on international level, a possibility which is also foreseen in the EU Waste Framework Directive, but only for mixed municipal waste [8]. With regards to collection of waste, harmonization shall be reached in terms of charging waste disposal fees based on the "polluter pays principle". Whereas for oily and greasy ship waste, the charges should be collected by Vignettes, to be paid by the skippers, the responsibility for cargo related waste shall be borne by the charterer or consignee. The disposal of household refuse is foreseen to be regulated on national level; most states accept a certain amount of household refuse from cargo vessel without additional payment at the moment, although a harmonization could be necessary in the future, e.g. if single states decides to introduce a charging system which might lead to higher waste amounts in other countries. 
In order to implement the uniform system for financing the disposal of oily and greasy ship waste, each state installs a National Institution, the costs of which are borne by the states themselves. Representatives of inland navigation shall be represented in the National Institution, a provision which guarantees the participation of the parties involved. Since the fee collection system shall be operated on international level, an International Clearance and Coordination Body (ICCB) is established. Its tasks are to carry out the financial clearance between the National Institutions involved, to check the network of waste reception facilities, make proposals for adaptation of Vignette Prices taking also into consideration impacts of waste prevention measures. The expenses of the ICCB shall be paid by deduction from the revenues as collected by the Vignette System (Art 10). General obligations for the boatsmen, but also crew and any person onboard, operators of terminals and waste reception facilities are requested to demonstrate utmost vigilance, in order to prevent polluting the waterway, limit the quantity of generated waste, and avoid mixing of different waste types (Art 11). At the same time, the vessels shall have the right to use the Reception Facilities (Art 12), a possibility, which is not self-evident at the moment. The last section of the core text then deals with administrative aspects and procedures, also determining the amendments to the Convention and its appendices. It has to be stated, that changes to a negotiated treaty might be hard to made, on the other hand, a certain flexibility with regards to adaptation of technical procedures might be required. As such, amendments to the Convention - if agreed at all - have to undergo the time consuming procedures of ratification, acceptance or approval of the states, whereas amendments to the Appendices, which detail the technical provisions do not require these procedures, but are adapted after a vote of the parties.

\subsection{Steps for implementation}

At the current state of development, feedback from all states participating in the $\mathrm{CO}-\mathrm{WANDA}$ project as well as from international observer organizations is collected, processed and being discussed at the already mentioned "International Implementation Board". This board, which has been established to bring together the responsible national authorities, the partner consortium which prepares the Convention and international observers, allows working on technical issues before official negotiations among states are started. Besides the administrative framework also strategies for subsequent implementation are discussed and drafted. Finally, the Consortium will end its work in September 2014 and hand over the IDSWC to the ministries in the countries to continue it on institutional level.

\section{Conclusions}

During WANDA project it was discovered that without appropriate transnational agreed legal instrument between Danube riparian countries ship waste management will be uncoordinated with fundamental risks for entire ecosystem. 
To avoid this, the administrative-legal framework has to be harmonized by an agreement on state level. This is planned to be reached by preparing an International Danube Ship Waste Convention (IDSWC) in the frame of the ongoing CO-WANDA project. During the project's research it was realised that on operational level the international coordination is necessary. As a part of this, an appropriate financial model was defined served by an Electronic Vignette System and with an optimized network of the waste reception facilities in the background. The research also made it clear that the goals can only be reached stepwise (due to lack of available information on waste generation) and with the contributions of the participating states as well as the support of European Union. On the other hand, awareness rising (for protecting the Danube and against illegal discharges) and education of skippers about proper waste handling is also crucial.

\section{References}

[1] www.wandaproject.eu.

[2] CDNI (2011): Convention on the collection, deposit and reception of waste produced during navigation on the Rhine and inland waterways. [online], Central Commission for Navigation on the Rhine. Available : http://www.cdni-iwt.org/10000000-en.html [04.07.2013].

[3] NEA (2012): Financing model for oily and greasy ship waste along the Danube. NEA Transport research and training. 2700 AG Zoetermeer, p. $65 \mathrm{ff}$.

[4] Via Donau - Österreichische Wasserstraßen-Gesellschaft mbH: National Report about Waste Prevention and pre-treatment onboard vessels - AT, Vienna, p.p. 29-35, 2014.

[5] Water Research Institute Bratislava: National Report about Waste Prevention and pre-treatment onboard vessels - SK, Bratislava, pp. 19-33, 2013.

[6] KTI - Institute for transport Sciences Non Profit Ltd: National Report about Waste Prevention and pre-treatment onboard vessels - HU, Budapest, pp. 15-22, 2014.

[7] Inland Navigation Development Center Ltd: National Report about Waste Prevention and pre-treatment onboard vessels - HR, Zagreb, p. 25-31, 2014

[8] Directive 2008/98/EC of the European Parliament and of the Council of 19 November 2008 on waste and repealing certain Directives, Article 16 (1). 